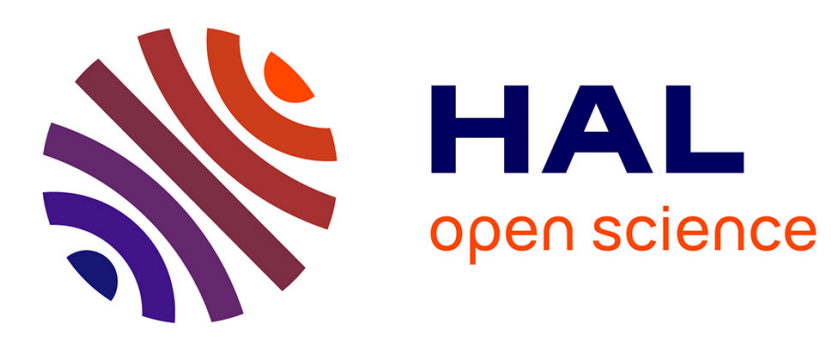

\title{
Control of the moisture content of growing media by time domain reflectometry (TDR)
}

Philippe Morel, Jean-Charles Michel

\section{To cite this version:}

Philippe Morel, Jean-Charles Michel. Control of the moisture content of growing media by time domain reflectometry (TDR). Agronomie, 2004, 24 (5), pp.275-279. 10.1051/agro:2004023 . hal-00886034

\section{HAL Id: hal-00886034 \\ https://hal.science/hal-00886034}

Submitted on 1 Jan 2004

HAL is a multi-disciplinary open access archive for the deposit and dissemination of scientific research documents, whether they are published or not. The documents may come from teaching and research institutions in France or abroad, or from public or private research centers.
L'archive ouverte pluridisciplinaire HAL, est destinée au dépôt et à la diffusion de documents scientifiques de niveau recherche, publiés ou non, émanant des établissements d'enseignement et de recherche français ou étrangers, des laboratoires publics ou privés. 


\title{
Control of the moisture content of growing media by time domain reflectometry (TDR)
}

\author{
Philippe MOREL*, Jean-Charles MiCHEL \\ UMR A 462 SAGAH (Sciences Agronomiques Appliquées à l'Horticulture), INRA-INH-Université d'Angers, 42 rue Georges Morel, BP 57, \\ 49171 Beaucouzé Cedex, France
}

(Received 24 June 2003; accepted 7 May 2004)

\begin{abstract}
The irrigation of pot crops requires considerable follow-up because the autonomy of the water reserve of the growing medium is low in relation to plant water requirements. Computerised systems for irrigation management are therefore under investigation. Time domain reflectometry (TDR) was used on different peat-based mixtures to which perlite or composted bark were added in volumetric ratios of 0,25 , 50,75 and $100 \%$. Calibration equations (linear or polynomial) established between the water content and dielectric constant were obtained for each mixture. Their precision is highly satisfactory $\left(\mathrm{R}^{2}>0.95\right)$, except for the mixture with $100 \%$ perlite. However, this method requires an equation per growing medium. We therefore attempted to establish a general formula that could be applied to binary peat-based mixtures. We tested second-order polynomial calibration equations, a function of the dielectric constant measured as well as the volume percent of complementary material added to the peat (bark or perlite). The precision of these equations is excellent for all mixtures $\left(\mathrm{R}^{2}>0.96\right)$. For all practical purposes, this approach would considerably simplify the use of TDR for computerised irrigation management because it would introduce only a limited number of parametric equations into the irrigation system.
\end{abstract}

irrigation management / TDR / pot crop / growing medium

\section{INTRODUCTION}

Irrigation management for pot crops is delicate because the quantity of water available to the plant is low as a result of the limited volume of the growing medium explored by roots. The water content of the growing medium varies rapidly, ranging from a value close to saturation after irrigation to a dryness level that is sufficient to cause the plant to wilt after several hours of evapotranspiration. The reverse phenomenon is observed with oxygen content at the level of the roots, where it may become and remain very low after irrigation if the climatic demand is limited, leading to a high risk of oxygen deficiency.

Water supply management and, as a result, the supply of air, is therefore crucial in a soilless culture. The measurement of water potential of the growing medium by tensiometry has been used with success over the last few years $[3,7]$. However, this method has met with reticence among professionals. One of the reasons for its lack of popularity is the relative complexity of its installation (from the probe to the electro-valve of irrigation) as well as the fragility of the tensiometer itself. The use of sturdier equipment would therefore remove one of the problems standing in the way of the development of these techniques.

Fairly recent research [4, 8] has shown the advantages of Time Domain Reflectometry (TDR) for directly measuring the soil water content. The principle of this technique is to measure the apparent dielectric permittivity of the soil (constant $\mathrm{K}_{\mathrm{a}}$ ), using a metal probe with an electromagnetic wave train running through it. The transmission time of these waves in the guide is a function of the length of the rods in the guide as well as of the dielectric constant of the material in which the probe is located. This constant depends on the type of matter (organic or mineral) as well and, above all, on its water content. Therefore, there is a direct relationship between the water content of the matter and the dielectric constant measured. The equation that determines this relationship is a polynomial according to Topp et al. [8], whereas it is linear for Ledieu et al. [4], where the calibration coefficients of these equations depend on the type of soil and especially on its organic matter content.

However, these equations are not directly applicable to growing media which often contain high proportions of organic matter. This has led different authors to look for the calibration equations the most well-suited to different materials. Among them, the work of Pépin et al. [6] on peat, Anisko et al. [1] on sand, composted bark and peat (alone or in a mixture), and Kipp and Kaarsemaker [2] on rockwool and granular material (perlite, coir dust and pumice stone), deserve special mention. For each type of material, specific equations were determined with excellent regression coefficients.

\footnotetext{
* Corresponding author: morel@angers.inra.fr
} 
The use of TDR to determine the water content of a growing medium seems possible on this type of material, provided that its calibration equation is known. However, in practice, the application of this method is more delicate than it would appear since growing media are often mixtures of several very different materials with variable volume percents. It is difficult to imagine the necessity of determining a specific calibration equation for each mixture. Therefore, the aim of our work was to see if calibration equations could be developed to include the measurement of $\mathrm{K}_{\mathrm{a}}$ as well as the volume percent of complementary material added to the peat and if the user's task could be simplified by simply indicating the type of mixture and the percent of the components, in the event that these formulas were included in the irrigation system.

\section{MATERIALS AND METHODS}

\subsection{Laboratory measurements}

In order to obtain reliable and reproducible moisture content measurements, samples were prepared according to the standardised European method, NFEN 13041 [9]. This method especially guarantees initial wetting and packing of the homogeneous growing medium. After preparation, each sample (cylinder of $100 \mathrm{~mm}$ in diameter and $100 \mathrm{~mm}$ in height) was subjected to increasing water potentials $(-1,-2,-3,-4,-5,-7.5,-10,-15$, -17.5 and $-20 \mathrm{kPa}$ ) on a suction table. The water content for each potential was estimated for three replications by weighing. In two other replications, an 8-cm-long TDR probe was introduced into the growing medium cylinder and kept in place throughout the entire trial. These probes were linked, via a multiplexer, to a device that served both as a wave transmitter and as a data acquisition centre at the same time (Trase 6050X1 from Soil Moisture Equipment Corp., Ca., USA). The values of the corresponding dielectric constant $\mathrm{K}_{\mathrm{a}}$ were also recorded at the same time as samples were taken to measure water content.

Measurements were made on different mixtures of Sphagnum peat, maritime pine bark and perlite (Tab. I). The peat, with a granulometry of approximately $10 \mathrm{~mm}$, came from the Baltic States. The bark, provided by the 'Terreaux de France- Faliénor' Company (Vivy, France), was composted and had a granulometry of less than or equal to $10 \mathrm{~mm}$.

\subsection{Models of adjustment for calibration curves}

Calibration curves were calculated for each material on the basis of real moisture content and $\mathrm{K}_{\mathrm{a}}$ taken from media placed on a vacuum table. Three regression models were used to evaluate the moisture content $\theta$ of the growing medium from $\mathrm{K}_{\mathrm{a}}$, two of which are commonly found in scientific literature:

- the polynomial equation of Topp et al. [8]

$$
\theta=\alpha_{0}+\alpha_{1} \mathrm{~K}_{\mathrm{a}}+\alpha_{2} \mathrm{~K}_{\mathrm{a}}^{2}+\alpha_{3} \mathrm{~K}_{\mathrm{a}}^{3}
$$

- the linear equation of Ledieu et al. [4]

$$
\theta=\beta_{0}+\beta_{1} \sqrt{K_{a}} \text {. }
$$

Table I. Mixtures used for measuring moisture content and $\mathrm{K}_{\mathrm{a}}$.

\begin{tabular}{lcc}
\hline $\begin{array}{l}\% \text { of perlite and bark in } \\
\text { mixture }\end{array}$ & Perlite & Composted bark \\
\hline 0 & PER0 & BARK0 \\
25 & PER25 & BARK25 \\
50 & PER50 & BARK50 \\
75 & PER75 & BARK75 \\
100 & PER100 & BARK100 \\
\hline
\end{tabular}

We would like to propose a third model, linear, simpler and not mentioned in the literature, but which deserves to be evaluated since it may be advantageous to the relatively narrow potential interval used $(-1$ to $-20 \mathrm{kPa})$ in the event that irrigation management by TDR is developed on growing media. This linear equation is solely a function of $\mathrm{K}_{\mathrm{a}}$ :

$$
\theta=\gamma_{0}+\gamma_{1} \mathrm{~K}_{\mathrm{a}}
$$

$\mathrm{K}_{\mathrm{a}}$ is the apparent dielectric permittivity of the growing medium, and $\alpha_{0}, \alpha_{1}, \alpha_{2}, \alpha_{3}, \beta_{0}, \beta_{1}, \gamma_{0}, \gamma_{1}$ are adjustment parameters.

\section{RESULTS}

\subsection{Calibration curves specific to the different mixtures}

Tables II, III and IV give the coefficient values for the three equation models and the nine growing media tested. They also indicate the precision of these equations by the corresponding determination coefficient $\mathrm{R}^{2}$. For most of the growing media, the polynomial equation gives very representative values of the real moisture content, with $\mathrm{R}^{2}$ greater than $98 \%$. Only the one applied to $100 \%$ perlite was a little less reliable. The linear equation of the Ledieu type [4] is also acceptable $\left(\mathrm{R}^{2}\right.$ greater than 0.96 in most of the cases), although it is a little less accurate, especially for mixtures with perlite. The simple linear equation also provides good results. For practical applications in soilless culture, these simpler models could therefore be used.

\subsection{Calibration curves determined by type of mixture}

The preceding equations are highly representative of each mixture but they also reveal the strong influence of the composition of the mixture on $\mathrm{K}_{\mathrm{a}}$. As can be seen in Figures 1 and 2, incorporating perlite or bark, even in limited quantities $(25 \%)$, leads to a major deviation from the curve. Therefore, for a $\mathrm{K}_{\mathrm{a}}$ value of 25 , for example, the moisture content is $51 \%$ for the peat but $60.5 \%$ for the mixture with $25 \%$ perlite and $66 \%$ with $25 \%$ bark. It is therefore clear that the user of a given growing medium who wants to use TDR to manage irrigation must know the exact characteristic equation of his mixture or run the risk of obtaining inaccurate results.

A more relevant solution would be to introduce complementary data into the model, making it possible to take the content 
Table II. Calibration coefficients for a polynomial type of equation - 8-cm probe placed vertically - 10 measurements per mixture.

\begin{tabular}{|c|c|c|c|c|c|}
\hline \multicolumn{6}{|c|}{$\begin{array}{c}\text { Equation model } \\
\theta=\alpha_{0}+\alpha_{1} K_{a}+v_{2} K_{a}^{2}+\alpha_{3} K_{a}^{3}\end{array}$} \\
\hline & $\alpha_{0}$ & $\alpha_{1}$ & $\alpha_{2}$ & $\alpha_{3}$ & $\mathrm{R}^{2}$ \\
\hline Peat $100 \%$ & 19.601 & 1.169 & 0.007 & -0.0001 & 0.9977 \\
\hline Bark $25 \%$ & 30.225 & -0.863 & 0.156 & -0.003 & 0.9970 \\
\hline Bark $50 \%$ & -22.979 & 7.549 & -0.223 & 0.003 & 0.9614 \\
\hline Bark $75 \%$ & 38.673 & -1.382 & 0.203 & -0.004 & 0.9970 \\
\hline Bark 100\% & 77.659 & -12.906 & 1.278 & -0.035 & 0.9903 \\
\hline Perlite $25 \%$ & -4.596 & 5.496 & -0.222 & 0.004 & 0.9929 \\
\hline Perlite $50 \%$ & 17.819 & 1.617 & -0.018 & 0.001 & 0.9949 \\
\hline Perlite $75 \%$ & 10.571 & 3.315 & -0.166 & 0.007 & 0.9847 \\
\hline Perlite $100 \%$ & 10.955 & 3.515 & -0.163 & 0.007 & 0.9333 \\
\hline
\end{tabular}

Table III. Calibration coefficients for a linear type of equation (function of $\left.\sqrt{K_{a}}\right)-8$-cm probe placed vertically -10 measurements per mixture.

\begin{tabular}{lccc}
\hline \multicolumn{4}{c}{ Calibration coefficients } \\
& \multicolumn{4}{c}{$\theta=\beta_{0}+\beta_{1} \sqrt{K_{a}}$} \\
Peat 100\% & $\beta_{0}$ & $\beta_{1}$ & $\mathrm{R}^{2}$ \\
Bark 25\% & -9.003 & 12.137 & 0.9966 \\
Bark 50\% & -27.526 & 18.602 & 0.9928 \\
Bark 75\% & -22.035 & 18.207 & 0.9572 \\
Bark 100\% & -9.811 & 15.721 & 0.9916 \\
Perlite 25\% & -4.573 & 14.697 & 0.9695 \\
Perlite 50\% & -22.616 & 16.875 & 0.9638 \\
Perlite 75\% & -6.578 & 12.988 & 0.9662 \\
Perlite 100\% & -2.895 & 11.778 & 0.9782 \\
\hline
\end{tabular}

\section{Calculated moisture content (\%)}

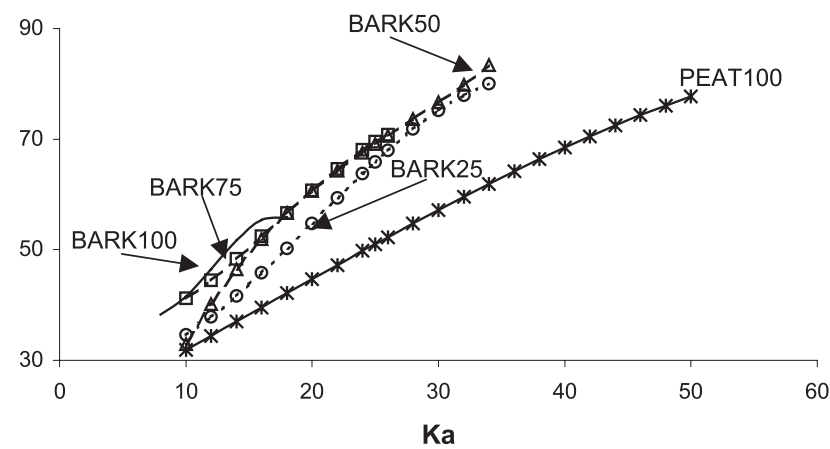

Figure 1. Relationship between calculated $\theta$ and $\mathrm{K}_{\mathrm{a}}$ for mixtures with bark. The obtained equations are highly representative of each mixture, but incorporated bark leads to a major deviation of the curve.

of material other than peat into account. It would thus be necessary for the user to introduce two simple data items into his irrigation programme (material and volume percent) instead of
Table IV. Calibration coefficients for a linear type of equation (function of $\mathrm{K}_{\mathrm{a}}$ ) -8 -cm probe placed vertically -10 measurements per mixture.

\begin{tabular}{lccc}
\hline \multicolumn{4}{c}{$\begin{array}{c}\text { Calibration coefficients } \\
\theta=\gamma_{0}+\gamma_{1} \mathrm{~K}_{\mathrm{a}}\end{array}$} \\
\hline Peat 100\% & $\gamma_{0}$ & $\gamma_{1}$ & $\mathrm{R}^{2}$ \\
Bark 25\% & 22.779 & 1.092 & 0.9889 \\
Bark 50\% & 12.620 & 2.096 & 0.9958 \\
Bark 75\% & 17.793 & 2.006 & 0.9445 \\
Bark 100\% & 21.425 & 1.937 & 0.9960 \\
Perlite 25\% & 22.375 & 1.985 & 0.9563 \\
Perlite 50\% & 12.494 & 1.982 & 0.9849 \\
Perlite 75\% & 14.989 & 1.890 & 0.9876 \\
Perlite 100\% & 13.481 & 2.078 & 0.9843 \\
\hline
\end{tabular}

Calculated moisture content (\%)

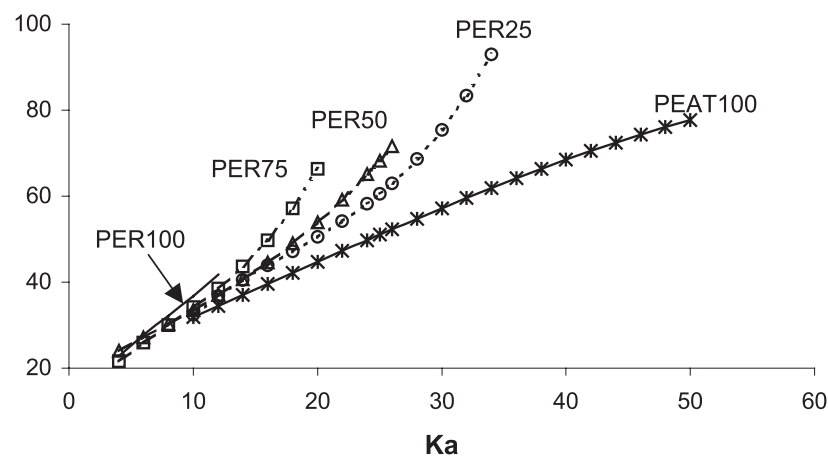

Figure 2. Relationship between calculated $\theta$ and $\mathrm{K}_{\mathrm{a}}$ for mixtures with perlite. The obtained equations are highly representative of each mixture, but incorporated perlite leads to a major deviation of the curve. 
Table V. Calibration coefficients for a third-order polynomial equation, a function of $\mathrm{K}_{\mathrm{a}}$ and of the percent of perlite or bark $(\mathrm{P})-50$ measurements per mixture.

\begin{tabular}{lcc}
\hline \multicolumn{3}{c}{ Equation model } \\
\multicolumn{3}{c}{$\theta=\theta_{0}+\alpha_{1} \mathrm{~K}_{\mathrm{a}}+\alpha_{2} \mathrm{~K}_{\mathrm{a}}{ }^{2}+\alpha_{3} \mathrm{~K}_{\mathrm{a}}{ }^{3}+\alpha_{4} \mathrm{P}+\alpha_{5} \mathrm{P}^{2}+\alpha_{6} \mathrm{P}^{3}$} \\
\hline Coefficients & Mixtures with perlite & Mixtures with bark \\
$\alpha_{0}$ & 4.052 & -6.879 \\
$\alpha_{1}$ & 2.499 & 3.488 \\
$\alpha_{2}$ & -0.024 & -0.047 \\
$\alpha_{3}$ & $6.9110^{-5}$ & $2.3710^{-4}$ \\
$\alpha_{4}$ & 0.418 & 0.464 \\
$\alpha_{5}$ & -0.007 & -0.0046 \\
$\alpha_{6}$ & $4.0710^{-5}$ & $1.7710^{-5}$ \\
$\mathrm{R}^{2}$ & 0.999 & 0.981 \\
\hline
\end{tabular}

Table VI. Calibration coefficients for a second-order polynomial equation, a function of $\mathrm{K}_{\mathrm{a}}$ and of the percent of perlite or bark (P) -50 measurements per mixture.

\begin{tabular}{|c|c|c|}
\hline \multicolumn{3}{|c|}{$\begin{array}{c}\text { Equation model } \\
\theta=\alpha_{0}+\alpha_{1} K_{\mathrm{a}}+\alpha_{2} \mathrm{~K}_{\mathrm{a}}^{2}+\alpha_{3} \mathrm{P}+{ }_{4} \mathrm{P}^{2}\end{array}$} \\
\hline Coefficients & Mixtures with perlite & Mixtures with bark \\
\hline$\alpha_{0}$ & 6.089 & -0.653 \\
\hline$\alpha_{1}$ & 2.343 & 2.797 \\
\hline$\alpha_{2}$ & -0.017 & -0.024 \\
\hline$\alpha_{3}$ & 0.191 & 0.367 \\
\hline$\alpha_{4}$ & -0.0011 & -0.002 \\
\hline $\mathrm{R}^{2}$ & 0.984 & 0.957 \\
\hline
\end{tabular}

introducing the regression coefficients for each mixture. We therefore looked for a simple relationship between $\theta$ and $K_{a}$, on the one hand, and the percent of perlite or bark in the mixture, on the other. Second- and third-order polynomial equations were tested. Tables V and VI give the results of these tests, with the corresponding $\mathrm{R}^{2}$ determination coefficients.

$\mathrm{R}^{2}$ is greater than 0.98 with perlite, regardless of whether the equation is second or third-order. The small difference observed between second- and third-order equations led us to choose the simplest, as can be easily seen in Figure 3.

The results for mixtures with bark are a little less precise but remain satisfactory because $\mathrm{R}^{2}$ is close to 0.96 in the two models. As in the case of perlite, the small difference observed between the second- and third-order equations led us to choose the simplest one. Figure 4 confirms the close correlation between the real moisture content and the moisture content calculated from a second-order polynomial equation.

\section{DISCUSSION}

The results obtained in the laboratory confirm that it is possible to obtain a very good estimate of the water content of a growing medium from the measurement of the dielectric con-

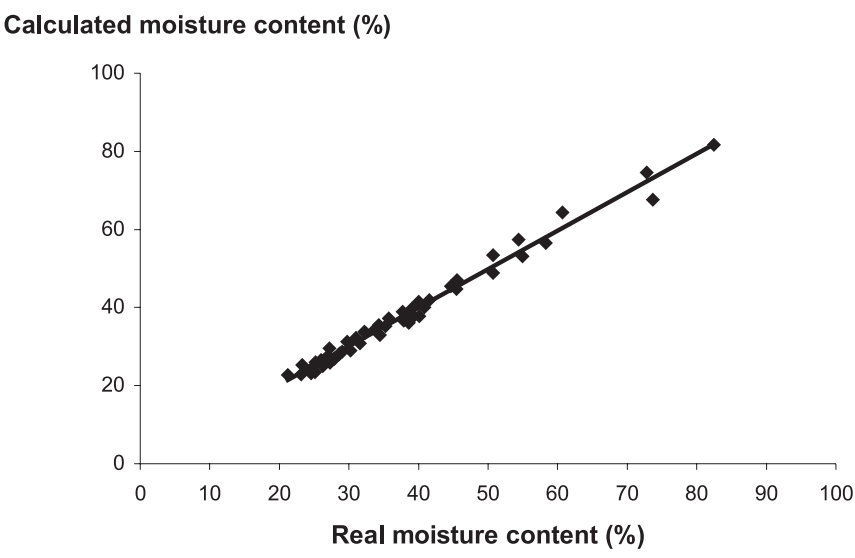

Figure 3. Linear regression between real moisture contents and calculated moisture contents according to a second-degree polynomial equation, as a function of $K_{a}$ and the percent of perlite $(y=0.9845 x$ +0.5866 with $\left.R^{2}=0.98\right)$. Note the very close correlation between the real and calculated moistures.

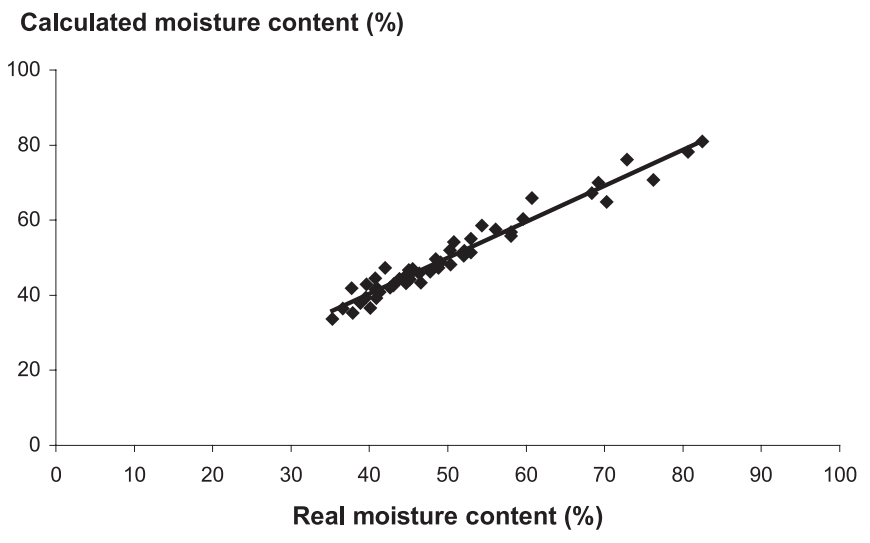

Figure 4. Linear regression between real moisture contents and calculated moisture contents according to a second-degree polynomial equation, as a function of $\mathrm{K}_{\mathrm{a}}$ and the percent of bark $(\mathrm{y}=0.9575 \mathrm{x}+$ 2.1337 with $\left.\mathrm{R}^{2}=0.96\right)$. The correlation between the real and calculated moistures is satisfactory but a little less close than for perlite.

stant $\mathrm{K}_{\mathrm{a}}$, by using a specific calibration equation for each growing medium. For moisture ranges commonly found in growing media (between -1 and $-20 \mathrm{kPa}$ ), linear and second- and thirdorder polynomials provide good results. This similarity of results between the different models can certainly be explained by the low amplitude of water potential variation in soilless systems (between -1 and $-15 \mathrm{kPa}$ in most cases) and water content, which always remains high (greater than $20 \%$ of the volume).

However, we also clearly demonstrated that the type of material had a strong influence on the value of $\mathrm{K}_{\mathrm{a}}$, independent of the water content. Even for totally organic materials such as peat/bark mixtures, differences in moisture content for the same value of $\mathrm{K}_{\mathrm{a}}$ may be as high as $20 \%$, depending on the volume percent of each component. This strong sensitivity to the type of mixture may stand in the way of its development as a method for irrigation management. Generally speaking, growing media are usually a mixture of different materials. It is 
therefore not possible to propose a specific calibration equation for each of them. This is why we tried to simplify the user's task by seeing if it was possible to find a single equation for mixtures made up of two materials, a case frequently encountered in cultivation practices. Therefore, $\mathrm{K}_{\mathrm{a}}$ is a factor in this equation as is the percent of complementary material added to the peat. On peat-based mixtures that contain increasing quantities of perlite and composted maritime pine bark, a second-order polynomial equation provides a totally satisfactory estimate of the moisture content. It is therefore valid to introduce the volume percent of perlite or bark into the calibration equation.

\section{CONCLUSION}

This work showed it is possible to measure precisely the moisture of a growing medium by TDR using a specific calibration equation (for each mixture) or a general formula (second-order polynomial calibration equations, a function of the dielectric constant $\mathrm{K}_{\mathrm{a}}$ and the volume percent of complementary material added to the peat). From a practical point of view, the use of TDR to manage irrigation would be simpler because the horticulturist would only need to provide the type of complementary material added to the peat and its volume percent since the computer would already have the corresponding calibration equation in its database. But one question still remains: what is the validity of these calibration equations based on measurements made in the laboratory, for use under growing conditions? We must question their long-term reliability, knowing that the characteristics of an organic growing medium can change over a period of time. A recent experiment, carried out with four different substrates on a Chrysanthemum $\times$ grandiflorum cultivation [5], showed the reliability of general calibration equations; but the length of growing time was short in this trial (only 13 weeks) and the growing media evolved very little during the cultivation. Therefore, experiments with longer growth cycles (several months) will be necessary to validate this method, before it is possibly used for computerised irrigation management of different pot or container crops.

Acknowlegements: The authors would like to thank Gilles Guillemain and Odile Douillet for their contribution to tests and analyses made within the framework of this study, and Mrs Wagman for the English translation of the text.

\section{REFERENCES}

[1] Anisko T., NeSmith D.S., Lindstrom O.M., Time domain reflectometry for measuring water content of organic media in containers, HortSci. 29 (1994) 1511-1513.

[2] Kipp J.A., Kaarsemaker S.C., Calibration of time domain reflectrometry water content measurements in growing media, Acta Hortic. 401 (1995) 49-55.

[3] Lachurie J., Morel P., Gestion de l'irrigation à partir des paramètres du substrat, in: ASTREDHOR, L'irrigation en pépinière hors-sol, Paris, 1999, pp. 39-52.

[4] Ledieu J., de Ridder P., de Clerck P., Dautrebande S., A method of measuring soil moisture by time domain reflectrometry, J. Hydrol. 88 (1986) 319-328.

[5] Morel P., Guillemin G., Mesure de la teneur en eau de différents substrats par TDR en culture de chrysanthème en pot, P.H.M. Rev. Hortic. 450 (2003) 36-41.

[6] Pépin S., Plamondon A.P., Stein J., Peat water content measurement using time domain reflectrometry, Can. J. Forest Res. 22 (1992) 534-540.

[7] Rivière L.M., Morel Ph., Loiseau M., Laury J.C., Mesure du potentiel hydrique des substrats de plantes en pots au moyen de tensiomètres. P.H.M. Rev. Hortic. 316 (1991) 33-39.

[8] Topp G.C., Davis J.L., Annan A.P., Electromagnetic determination of soil water content: measurements in coaxial transmission lines, Water Resour. Res. 16 (1980) 574-582.

[9] NF EN 13041. Soil improvers and growing media - Determination of physical properties - Dry bulk density, air volume, water volume, shrinkage value and total pore space, AFNOR (2000). 